Article

\title{
Cloning and Expression Characteristics of the Pig Stra8 Gene
}

\author{
Xiaoyan Wang ${ }^{\dagger} *$, Tingfeng Chen ${ }^{\dagger}$, Chengyi Song ${ }^{\dagger}$, Bo Gao ${ }^{\dagger}$ and Yani Zhang ${ }^{\dagger}$ \\ College of Animal Science \& Technology, Yangzhou University, Yangzhou 225009, China; \\ E-Mails: ctf20070702664@126.com (T.C.); cysong@yzu.edu.cn (C.S.); bgao@yzu.edu.cn (B.G.); \\ ynzhang@yzu.edu.cn (Y.Z.) \\ $\dagger$ These authors contributed equally to this work. \\ * Author to whom correspondence should be addressed; E-Mail: wxyan@yzu.edu.cn; \\ Tel.: +86-514-8797-9034; Fax: +86-514-8735-0440.
}

Received: 19 May 2014; in revised form: 16 June 2014 / Accepted: 16 June 2014 /

Published: 15 July 2014

\begin{abstract}
Stra8 (Stimulated by Retinoic Acid 8) is considered a meiotic gatekeeper gene. Using reverse transcriptase PCR and rapid amplification of cDNA ends (RACE), the complete sequence of the pig Stra8 gene was cloned. Bioinformatics analyses of this sequence were performed. Using semi-quantitative methods, the expression characteristics of Stra8 in Testis, cauda epididymis, body epididymis, caput epididymis, seminal vesicles, prostate gland, Cowper's gland, heart, liver, spleen, lung, kidney, stomach, hypothalamus, pituitary gland, cerebrum, cerebellum, and hippocampus of adult Meishan boar and sow tissues were examined. The expression pattern in the testis of 2-, 30-, 60-, 90-, and 150-day old Meishan boars were analyzed using real-time PCR. We constructed a eukaryotic expression vector for the Stra8 gene and used it to transfect NIH-3T3 cells and third generation pig spermatogonial stem cells (SSCs) cultured in vitro. Testes weight and sperm count in the cauda epididymis were evaluated at various time points. The results showed that the length of the pig Stra8 gene cDNA was 1444 bp encoding 366 amino acids with one typical helix-loop-helix (HLH) domain. It is testes-specific expression. Expression was first detected in boar testis starting at day 2 , and its expression significantly $(p<0.05)$ increased with age and body weight. When NIH-3T3 cells and pig SSCs were transfected with the eukaryotic expression vector EGFP (enhanced green fluorescent protein)-N1-pStra8, it was expressed in the cytoplasm of NIH-3T3 cells. However, in SSCs, Stra8 was expressed predominantly in cytoplasm and few in nucleus. Our data suggest that perhaps Stra 8 acts as a transcription factor to initiate meiosis in young boar.
\end{abstract}


Keywords: Stra8; Meishan pig; expression

\section{Introduction}

In mammals, haploid gametes must undergo meiosis from germ cells whether they are male or female. The timing of meiosis entry differs significantly between male and female germ cells. At nearly 13.5 days post-coitum (dpc), female primordial germ cells (PGCs) initiate meiotic process and then arrest at the dictyate stage, whereas male PGCs arrest at the G0/G1 stage of the cell cycle in the mitotic process. After birth, male PGCs resume mitotic proliferation and subsequently enter meiosis during puberty [1-4]. Retinoic acid (RA) has been proven to induce meiotic initiation for PGCs $[5,6]$.

Vitamin A deficiency results in meiotic failure and the accumulation of undifferentiated spermatogonia in prepubertal mouse testis [7]. RA is an active metabolite of Vitamin A and a vital signaling molecule for many physiological processes [8]. The effects of RA were mediated by retinoic acid receptor A (RARA) through activating Mafb expression to germ cell differentiation [9]. It can induce expression of Stra8 (Stimulated by Retinoic Acid 8) leading to the onset of meiosis in both male and female gonads. Stra8 was first identified in 1995 as one of the RA-responsive genes in P19 embryonic carcinoma cells [10,11]. In female PGCs, RA can induce Stra8 gene expression at $12.5 \mathrm{dpc}$ and lead to meiotic initiation. However, in male fetal testes, CYP26B1, produced by pre-Sertoli cells, can metabolize RA to prevent male PGCs from entering meiosis. Therefore, male PGCs maintain mitosis and after birth, they can enter into meiosis with expression of Stra8 [6,12,13]. Exogenous RA can induce or enhance Stra8 gene expression in SSCs cultured in vitro [14-17].

Knockout of the Stra 8 gene blocks entry into meiosis in both embryonic ovaries and pubertal testes $[18,19]$. The early mitotic development of germ cells appears normal in juvenile C57BL/6 male mice. However, these cells cannot finish meiosis and have no leptotene, zygotene, or pachytene spermatocytes cells in testes. Therefore, Stra 8 is necessary for processes including chromosomal cohesion, synaptonemal complex formation, and recombination and acted as a meiotic gatekeeper gene [19,20]. Gene knockdown and transgenic models of some genes involved in RA synthesis and metabolism also prove that Stra8 gene expression is induced by RA and is important for the onset of meiosis [7,21]. The genetic variant and expression change of Stra 8 showed higher risk of spermatogenic impairment in the groups of infertility, which implies Stra8 is critical in spermatogenesis [22,23].

The Meishan pig is notable for its high prolificacy and early sexual maturity [24]. In male Meishan pigs, the onset of puberty (spermatogenesis) starts at a much younger age (56-84 days) than that of other conventional pigs (120-180 days) [25]. Spermatogenesis begins from PGC meiosis after birth with onset of boar puberty. Stra 8 gene is considered a meiotic gatekeeper gene. In order to better understand the characteristics of this gene, we cloned it from Meishan boar testes and studied its spatio-temporal expression pattern. 


\section{Results and Discussion}

\subsection{Cloning of Pig Stra8}

PCR amplification using the Meishan boar testes cDNA yielded $1108 \mathrm{bp}$ middle sequence, $254 \mathrm{bp}$ 5 ' end, and 157 bp 3' end. The fragments were cloned and sequenced. The full-length Stra 8 gene cDNA was $1444 \mathrm{bp}$, assembled using the three sequences. Basic Local Alignment Search Tool (BLAST) searches showed that it had the highest sequence identity to mammalian Stra8. The pig Stra 8 cDNA was submitted to the NCBI GenBank (accession number JQ965783).

Using Open Reading Frame Finder (ORF Finder), the 1444-bp pig Stra8 cDNA contains $147 \mathrm{bp}$ 5' end, 1101 bp ORF, and 196 bp 3' end. It encodes a protein of 366 amino acids with a molecular mass of $41.04 \mathrm{kDa}$. The sequence can be found with a polyadenylation signal sequence (TATAAA) and a polyadenylation tail (Figure 1).

Figure 1. Nucleotide and amino acid sequence of pig Stra8. Stop codon is shown as “*”.

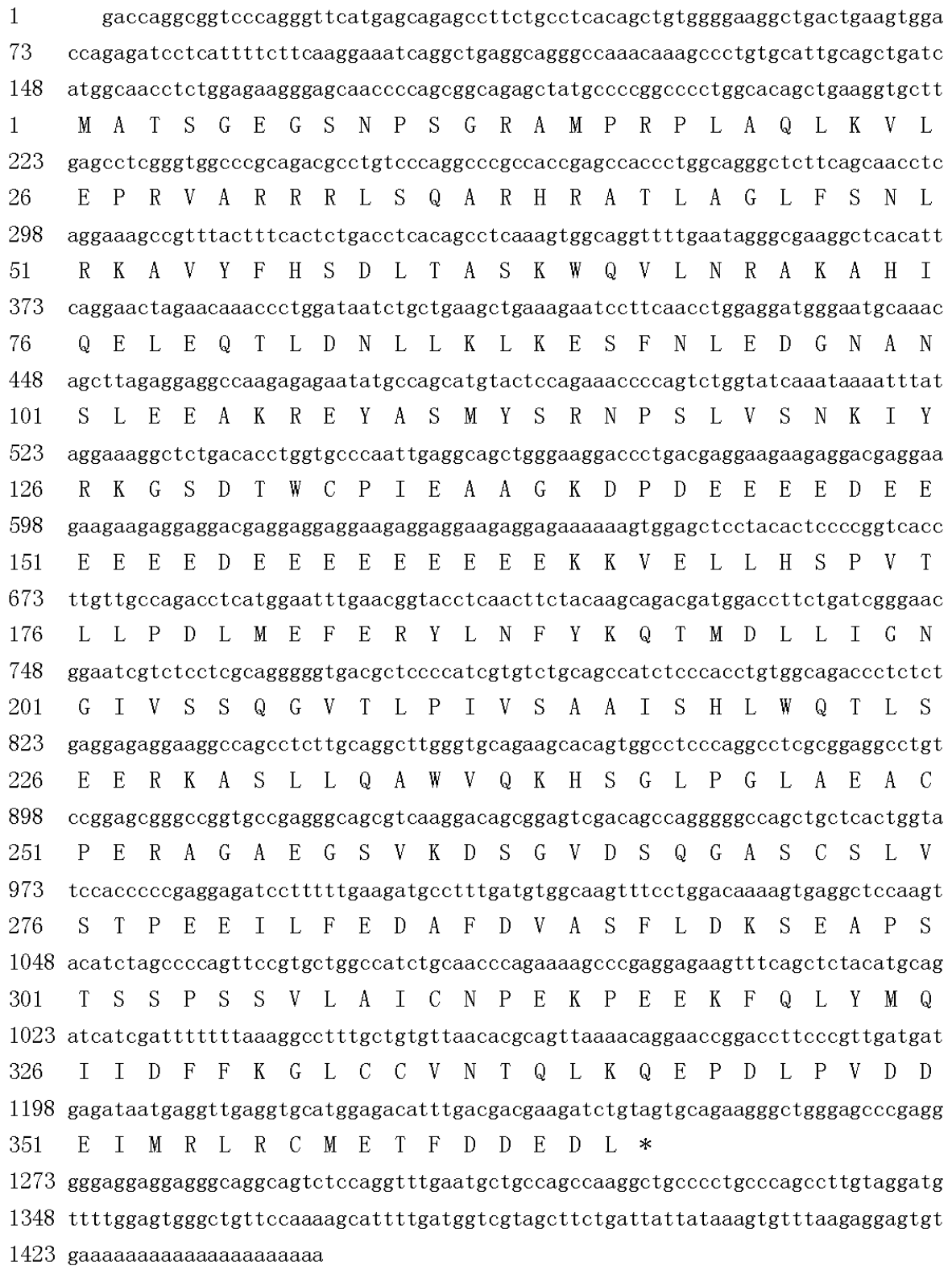


Among the secondary structure elements, alpha helices were predominant, followed by loops. Stra8 is not a secreted protein, nuclear protein, or DNA binding protein. Two coiled-coil regions range from amino acids 62-95 and 143-170 based on the predicted amino acid sequence by COILS (SIB, Lausanne, Switzerland). Based on predictions by SMART (EMBL, Heidelberg, Germany), amino acids 34-84 of pig STRA8 is a helix-loop-helix (HLH) structure and amino acids 140-172 is a coiled-coil domain (Figure 2). Transmembrane domains and signal peptides were not found in the polypeptide chain.

Figure 2. Analysis of the functional domains of the Stra 8 amino acid sequence. (A) using COILS program; (B) using SMART program.

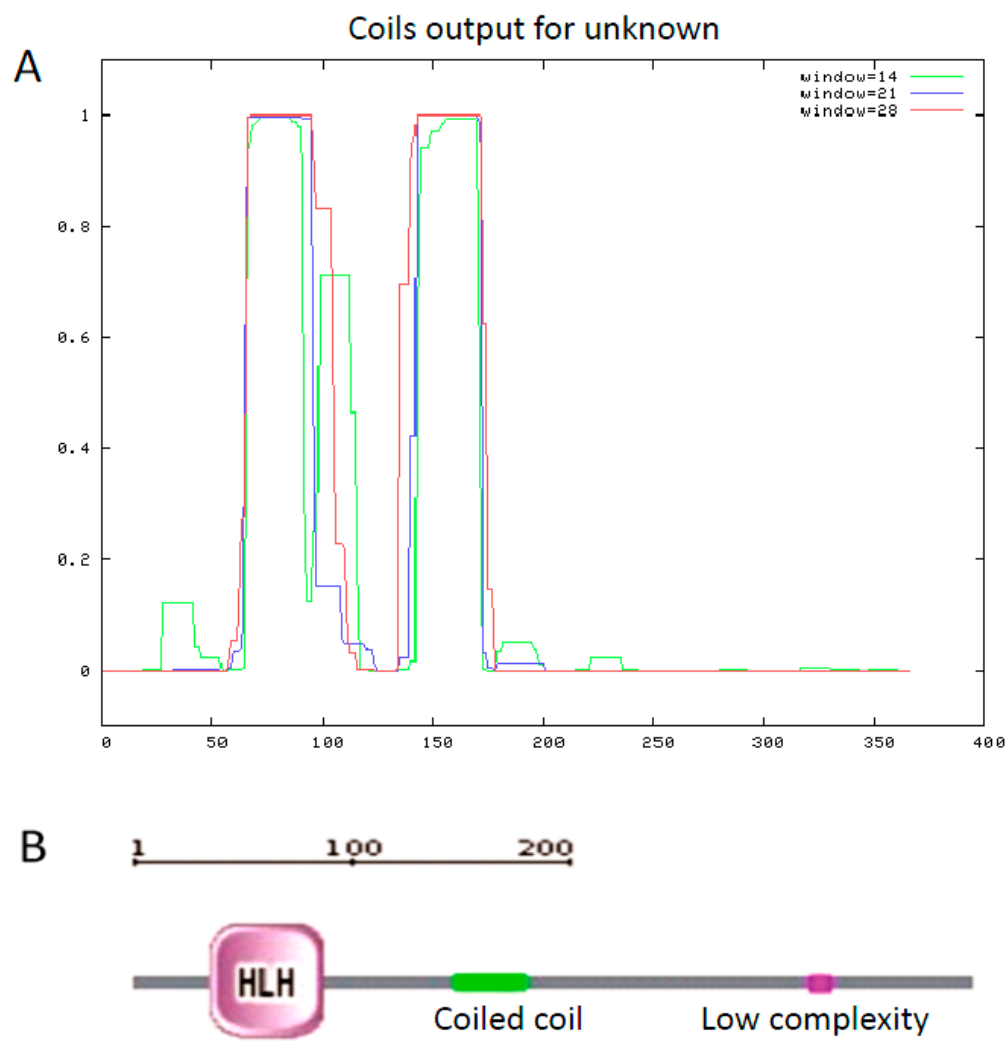

\subsection{Multiple Sequence Alignments and Phylogenetic Relationships}

The pig STRA8 amino acid sequence shares the highest similarity (78.4\%) with mouse, and has the lowest homology (45.4\%) with chicken (Table 1). Using the Clustal W program to analyze Stra8 amino acid homology among different species, it was highly conserved in the predicted HLH structure and 3 ' end between pig and human, rat, mouse, and cattle. There is a glutamic acid rich domain in the middle of the pig STRA8 amino acid sequence that exists only in rat and mouse STRA8 (Figure 3). A phylogenetic tree was constructed using DNAMAN to analyze phylogenetic relationships. Pig STRA8 clusters with domestic breeds (cattle and horse), but not with humans and other primates such as chimpanzee and Sumatran orangutan. Pig STRA8 was least related to chicken (Figure 4). 
Table 1. Homology analyses of STRA8 amino acid sequence.

\begin{tabular}{ccc}
\hline Species & Similarity & GenBank Accession Number \\
\hline Homo sapiens & $66.5 \%$ & NM_182489.1 \\
Rattus norvegicus & $72.1 \%$ & XM_575429.2 \\
Mus musculus & $78.4 \%$ & NM_009292.1 \\
Bos taurus & $57.8 \%$ & XM_001253649.1 \\
Canis lupus familiaris & $66.4 \%$ & XM_847727.2 \\
Gallus gallus & $45.4 \%$ & XM_416179.3 \\
Equus caballus & $75.0 \%$ & XM_001914766.1 \\
Pongo abelii & $66.8 \%$ & XM_002818472.1 \\
Pan troglodytes & $66.6 \%$ & XM_001144872.2 \\
\hline
\end{tabular}

Figure 3. Amino acid sequence alignment of STRA8. M-STRA8: mouse STRA8; R-STRA8: rat STRA8; H-STRA8: human STRA8; B-Stra8: bovine STRA8; S-STRA8: pig Stra8. HLH: helix-loop-helix. "*” the amino acid is identical in this position; ":" the amino acid in this position is conserved; "." the amino acid in this position is semi-conserved. Pig HLH structure is underlined and Coiled coil is bold.

M-Stra8
R-Stra8
H-Stra8
B-Stra8
S-Stra8
M-Stra8
R-Stra8
H-Stra8
B-Stra8
S-Stra8

M-Stra8
R-Stra8
H-Stra8
B-Stra8
S-Stra8

M-Stra8
R-Stra8
H-Stra8
B-Stra8
S-Stra8
R-Stra8
H-Stra8
M-Stra8
S-Stra8
R-Stra8
H-Stra8
B-Stra8
S-Stra8
R-Stra8
H-Stra8
S-Stra8
M-Stra8
R-Stra8
H-Stra8
B-Stra8
S-Stra8

M-Stra8
-Stra
H-S

MLHCFFHCLHLIGPPPRILIGCGPRDTLRLVRAPVLKSGPVGRHCVWHVRLVTRCHHWHG

MATPGEGNQPSDDGAPQPLAQLQKLEPRVVRRRLS 35 --_---_--_--_-_-_---_--MATPGEGNQPRDDGAPQPVPQLQQLEPRVARRRLS 35 ---MGKIDVDKILFFNQEIRLWQL IMATPEENSNPHDRATPQLPAQLQELEHRVARRRLS 57 FPRPVCPGVHLPARGQAKPSTLQLLMETARKGGNAGRRMMPR ---VLQELEQRVARRRLS 117

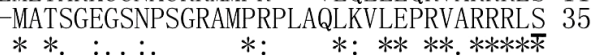

QARHRATLVGLFNNLRKAVYSQSDITASKWQVLNRTKIHIQEQEESLDKLLKLKASFNLQ 95 QARHRATLVGLFNNLRKTVYSQSDLTASKWQVLNKAKSHIQELEGSLDNLLKLKGFFNLQ 95 QARHRATLAALFNNLRKTVYSQSDLIASKWQVLNKAKSHIPELEQTLDNLLKLKASFNLE 117 QARHRATLSGLFGNLRKAVYSHSDLTASKWQVLNKAKNHIQELEQTLDNLLKLKGYFNLE 177 QARHRATLAGLFSNLRKAVYFHSDLTASKWQVLNRAKAHIQELEQTLDNLLKLKESFNLE 95 *********;******:**:**: $* * * * * * * *: ; * * * * *: * *: * * * * * * * *:$ HLH

DGNPNSLEEVKEEYARMYSENDSVFLNSFLQDSPPEWFPSEAVGPDAEEEGEEEGEEEGE 155 DGNPNTLEEVKEEYARMYSENESVFLNSFPQNSPPAWLPPEAVGPDAEEGG----_---- 146 DGHASSLEEVKKEYASMYSGND--_--SFPQNGSSPW--_-_-_-_-_-_-_-_-_-_-_-_- 149 DGNANSLEEAKKKYASMYSRNP-----SAPSGGHCPFG--_-_-_-_-_-_-_-_-_-_-_- 210 DGNANSLEEAKREYASMYSRNPSLVSNK IYRKGSDTWCPIEAAGKDPDEEE-------- 146 $* *: . .: * * * . * .: * * * * * *$

EGEEEEEGDEEGEEEEENGEEREVEEYQEEEEEEEEEEKKVDLSHSSSTLLPDLMEFERY 215 EDEEEEEEDEEEEEEEEEKKVELLHSPVTLIPDLOCRY 213 Coiled coil

LNFYKQTMDLLTMNSI ISAHEVTLPIVSAAISHLWQTLSEEKKARLLQVWEQQHSAFADL 275 LNFYKQTMDLLTMNSI ISAQEVTLPIVSAA ISHLWQTLSEEKKARLLQVWEQQHSTFSDL 248 LNFYKQTMDLLTGSGIITPQEAALPIVSAAISHLWQNLSEERKASLRQAWAQKHRGPATL 210 LNFYKRTMDFLIRNEF ISSNEVTLPIVSAA ISHLWQTFSEERKTF ILQALERTQKG---L 270 LNFYKQTMDLLIGNGIVSSQGVTLPIVSAA ISHLWQTLSEERKASLLQAWVQKHSGLPGL 246

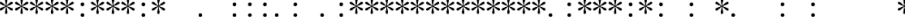

TEACLELAGVEGSMKDSGVDSQGASCSLESTPEEILFEDAFDVASFLDKSEAQHMSNISA 335 TEACLELAGAEGSMKDSGVDSQGASCSLDSTPEEILFEDAFDVASFLDKSEAQRLSNISA 308 AEACREPACAEGSVKDSGVDSQGASCSLVSTPEEILFEDAFDVASFLDKSEVPSTSSSSS 270 VGSCPEPACPEGSVKDSGVDSQGASCSLISTPEEILFEEAFDVASFLDKSEAPGTSSPST 330 AEACPERAGAEGSVKDSGVDSQGASCSLVSTPEEILFEDAFDVASFLDKSEAPSTSSPSS 306 . : $* * * * * *: * * * * * * * * * * * * * * * * * * * * * * * * * * * * * * * * * * * * . \quad *$. $*$ :

MFATCNSENPEEKFQLYIQLIEFFKSLGCVNTPLNQEPEPPDDDDAMLLKCLETFDDL-- 393 VFASCNSENLEEKFQLYIQI IEFFKGLGCVNTPLNQEPDPPVDDDVMLLKCLETFDDEDL 368 VLASCNPENPEEKFQLYMQI INFFKGLSCANTQVKQEASFPVDEEMIMLQCTETFDDEDL 330 SLAVCNSKKPEDKFHL YVQIVDFFKDFCCVDTQVKQEPDLPVDDEMIMLRCTETFDDEDL 390 VLAICNPEKPEEKFQL YMQI IDFFKGLCCVNTQLKQEPDLPVDDEIMRLRCMETFDDEDL 366 $: * * * .:: *: * *: * *: * *:: * * * .: * .: *:: * * . . * *::: * * * * * * * *$ 
Figure 4. Phylogenetic analyses of the Stra8 gene.

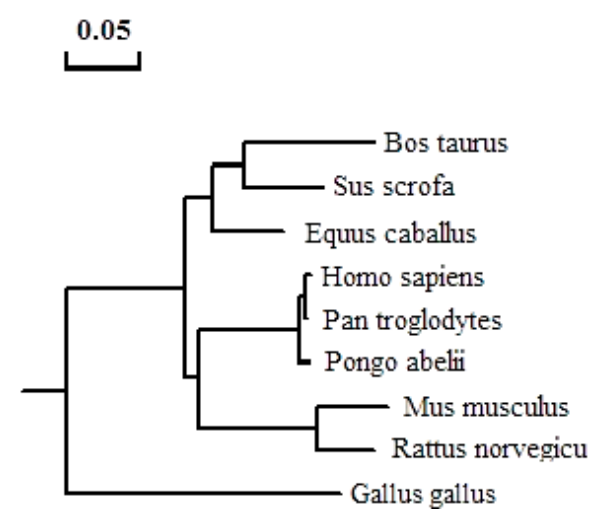

\subsection{Stra8 mRNA Distribution}

Semi-quantitative RT-PCR was performed to analyze Stra8 gene expression patterns in testis, cauda epididymis, body epididymis, caput epididymis, seminal vesicles, prostate gland, Cowper's gland, heart, liver, spleen, lung, kidney, stomach, hypothalamus, pituitary gland, cerebrum, cerebellum, and hippocampus of adult boars and sows. Stra8 expression was exclusively expressed in the testes (Figure 5).

Figure 5. Expression of Stra 8 mRNA in reproductive tissues from Meishan boar and sow. M: DL2000; 1: Testis; 2: Caput epididymis; 3: Body epididymis; 4: Cauda epididymis; 5: Seminal vesicle; 6: Prostate; 7: Balbocavernous glands; 8: Negative control; 9: Ovary; 10: Uterus corners; 11: Uterus; 12: Oviduct; 13: Heart; 14: Liver; 15: Spleen; 16: Lung; 17: Kidney; 18: Stomach; 19: Hypothalamus; 20: Pituitary gland; 21: Cerebrum; 22: Cerebellum; 23: Hippocampus.
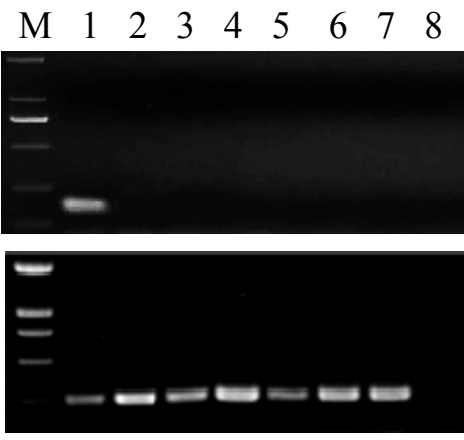
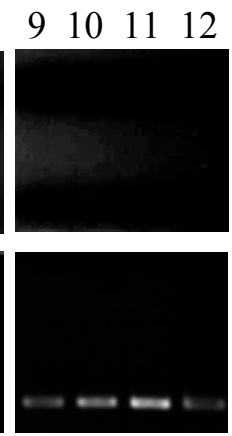
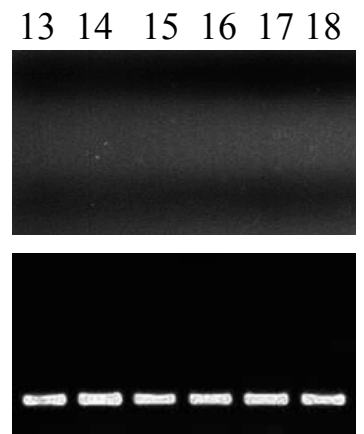

$\begin{array}{lllll}19 & 20 & 21 & 22 & 23\end{array}$

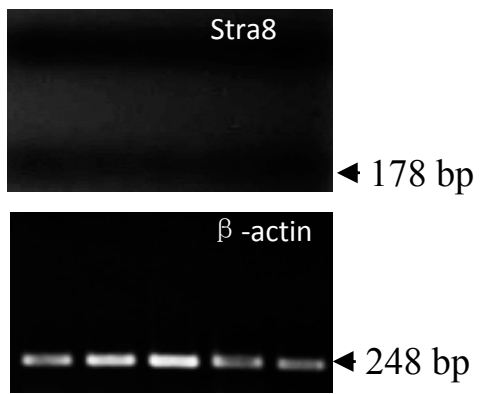

\subsection{Developmental Expression Pattern of Stra8, Testes Weight, and Sperm Count}

Using real-time quantitative PCR, Stra 8 mRNA expression was evaluated in pig testes at different ages. $\beta$-actin was used as an internal reference and Stra 8 expression at 150 days were used as a control. Testes Stra 8 mRNA was expressed from 2 days post partum and increased significantly from day 60 until it peaked at day 150 ( $p<0.01$; Figure 6A). Sperm with complete morphological characteristics were observed until day 60 in cauda epididymis (Figure 6B). The sperm count increased dramatically on days 90 and $150(p<0.01)$. There were no differences among 2-, 30-, and 60-day testis weight. However, after day 60, testis weight increased significantly $(p<0.01)$ (Figure 6C). It is 
therefore possible that the high levels of Stra 8 mRNA expression on day 60 were in preparation for the subsequent production of large numbers of sperm and sex maturity.

\subsection{Subcellular Localization of Pig Stra8 in NIH-3T3 Cells and Pig SSCs (Spermatogonial Stem Cells)}

Stra8 ORF fragment were inserted into EGFP-N1 vector. After double enzyme digestion and sequencing, the correctly inserted Stra 8 ORF fragment was named pEGFP-N1-Stra8. In order to investigate the subcellular location and function of pig Stra 8 in meiosis, the protein was equipped with a GFP tag fused to its $C$-terminus and transiently transfected into NIH-3T3 cells and pig SSCs. Subsequent analyses using fluorescence microscopy revealed that pEGFP-N1-Stra 8 was exclusively localized to the cytoplasm in 3T3 cells (Figure 7A) and predominantly localized to the cytoplasm in pig SSCs (Figure 7B).

Figure 6. Expression of Stra 8 mRNA in testis, the sperm count in cauda epidydimis, and testes weight of Meishan boars at various time points. (A) Expression of Stra8 mRNA; (B) Sperm count; and (C) Testes weight. Significant increases are denoted with " ***" (compared with their previous stage, $p<0.01$ ).
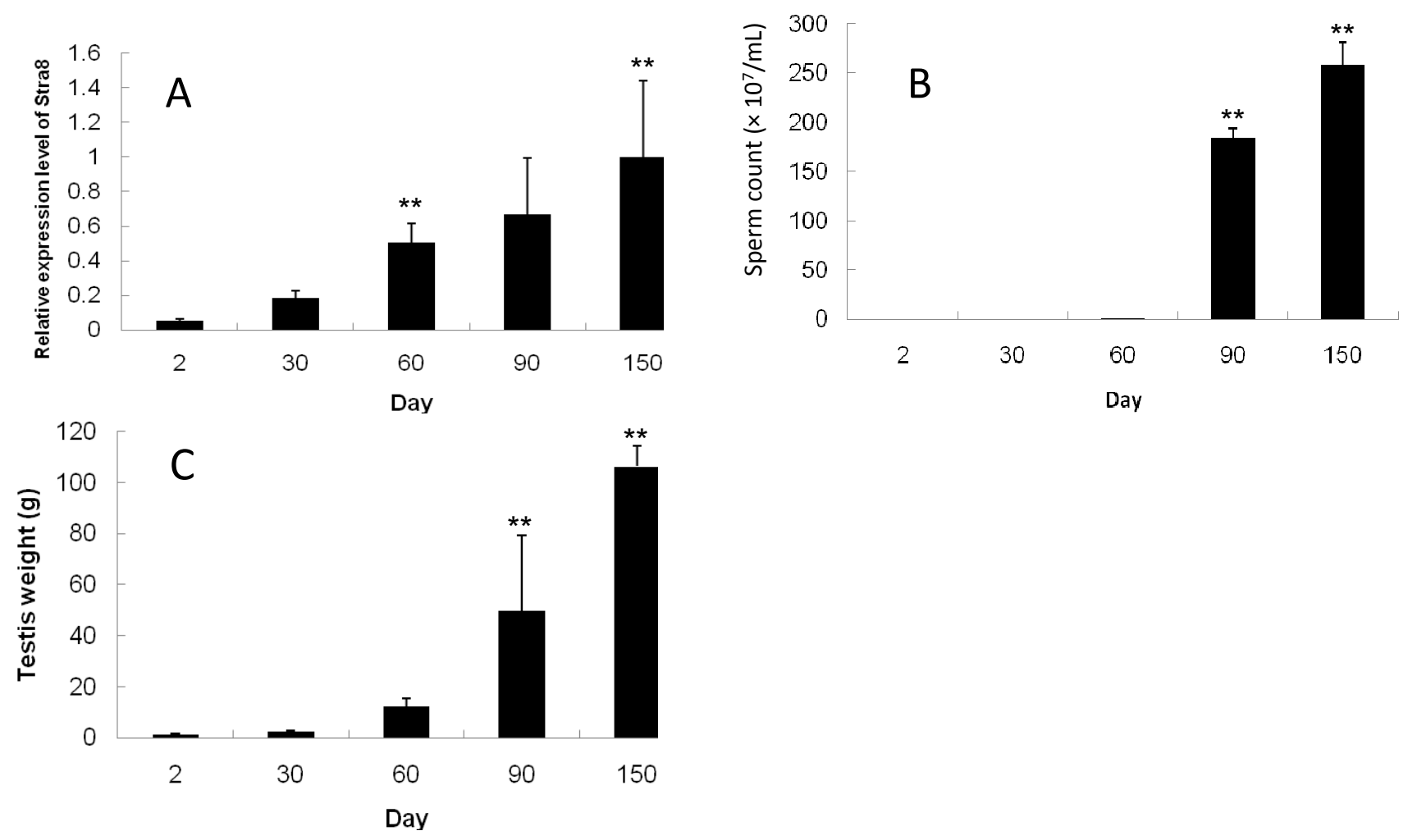
Figure 7. NIH-3T3 cells and pig SSCs (spermatogonial stem cells) transiently expressing EGFP-N1-Stra8. (A) NIH-3T3 cells transfected with pEGFP-N1-Stra8; (B) Pig SSCs transfected with pEGFP-N1-Stra8 $(\times 200)$.
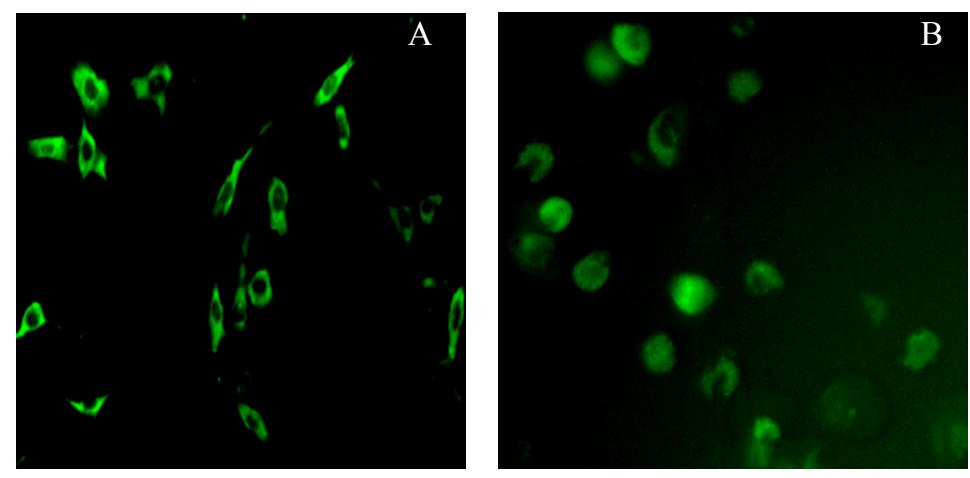

\subsection{Discussion}

The Stra8 gene is one of 50 RA-responsive genes isolated from a P19 pluripotent embryonal carcinoma (EC) cell line treated with RA. The expression of Stra8 in spermatogonia coincides with the transition from undifferentiated type A spermatogonia to differentiated type A1 spermatogonia. Stra8 cDNA (1455 bp) is located on mouse chromosome 6 and encodes a putative 393 amino acid protein containing a glutamic acid-rich domain [9]. Human Stra8 mRNA is 993 bp and encodes a 330 amino acid protein that maps to chromosome 7 [26]. In this study, based on GenBank Expressed Sequence Tags (ESTs), we used RT-PCR, 5'-RACE, and 3'-RACE to obtain a 1444 bp pig Stra8 cDNA that encodes a putative 367 amino acid protein. Similar to the mouse amino acid sequence, the putative pig Stra 8 amino acid sequence has a glutamic acid-rich domain. This domain can form coiled-coil structures as shown using COILS and SMART. Using Protscale, the domain is highly hydrophilic, perhaps to improve the stability of the coiled-coil domain in the aqueous cytoplasmic environment [27]. Glutamic acid-rich domains were found in pig, mouse, and rat Stra 8 amino acid sequences, but not in human and cattle. The function of this domain requires further study. The Stra 8 HLH structure identified by SMART had relatively high conservation between pig and other species. The HLH motif comprises two amphipathic $\alpha$-helices of 15-16 residues separated by a loop and is responsible for dimerization of a class of transcription factors called HLH proteins [28]. Therefore, it is possible that Stra8 acts as a transcription factor during the onset of spermatogenesis.

Oulad-Abdelghani et al. (1996) [9] showed that Stra8 expression is restricted to adult mouse testes. After treatment with RA, P19 and F9 cells, as well as SSCs, began to express Stra8 mRNA within $24 \mathrm{~h}$. These results show that RA can induce some cell lines that are not germ cells to express Stra8. Human Stra8 is also expressed selectively in testes [26]. In this study, we found that among 19 Meishan boar tissues and four Meishan sow reproductive tissues, Stra 8 is expressed only in adult testes. Mouse Stra 8 could be detected in germ cell as early as five days postpartum and its expression must coincide with the initiation of meiosis in postnatal testes [29]. When we evaluated the developmental expression pattern in postnatal Meishan boar testes, Stra 8 mRNA can be detected at two days postpartum. However, its expression increased significantly with the age and bodyweight. Meishan, a Chinese native breed famous for its prolificacy, undergoes pubertal development at a younger age (56-84 days) than conventional breeds (120-180 days) for boar [25]. Spermatocytes and spermatids increased significantly in seminiferous 
tubules of Erhualian boar from day 60 and sperm appears [30]. Based on sperm counts in cauda epidydimis from Meishan boar, sperm with recognizable characteristics emerged at day 60 in this study. The spermatogenic cycle ranges from the period of spermatogonia launch meiosis until sperm finally develop with integrated heads and tails in vivo. The pig spermatogenic cycle is 42 days. We conclude that spermatogonia in Meishan boar testis must initiate meiosis before day 18 postpartum. Stra8, a meiotic gatekeeper gene, is expressed in premeiotic germ cells and can be detected at two days postpartum in Meishan boar. Whether Stra8 levels could impact the onset of meiosis 2-18 days after birth needs be studied further. Sperm can be first found in semen at different time points in Erhualian boar (60-75 days) and Jiling black pig (a breed inbred with Chinese native pigs and western-introduced pigs, 134-143 days) [31]. These time points haveeconomic importance to boar breeding, and whether they are attributed to the start of meiosis initiation or another mechanism is unclear. Single nucleotide changes in Stra8 have been detected that are absent in men with normozoospermia [32]. Because subsequent functional analyses of the changes were likely not the cause of infertility, it can be concluded that mutations are rarely detected in men with fertility problems. Therefore, further research is necessary to determine the impact of genetic causes on boar meiosis initiation.

In order to study the mechanism of Stra8 gene function in spermatogenesis in vitro, we constructed EGFP-recombinant expression vectors and transfected them into NIH-3T3 cells. The fusion protein was only localized in the cytoplasm. This result is similar to Miyamoto et al. (2002) [26] and Oulad-Abdelghani et al. (1996) [9] because it is not localized in other cytoskeletal structures. However, when the plasmid was transfected into pig SSCs, fluorescence was observed in the cytoplasm as well as the nucleus. Stra8 has previously been found in the nucleus in P19 cells and F9 cells [33]. In this study, we found pig Stra8 has a HLH structure based on sequence analyses and is located in the nucleus of some SSCs. Therefore, it can be predicted that Stra 8 may be act as a transcription factor to initiate pig SSCs meiosis. However, because the transfection efficiency is relatively low, we need to improve this technical issue and study Stra8 localization further.

\section{Experimental Section}

\subsection{Animals and Samples}

Meishan boars and sows were obtained from six multiparous dams and were housed together prior to sacrifice. All piglets were weaned at 28 days and fed standard pelleted rations. The animal use protocol was approved in accordance with the University Council on Animal Care guidelines.

Testis, cauda epididymis, body epididymis, caput epididymis, seminal vesicles, prostate gland, Cowper's gland, heart, liver, spleen, lung, kidney, stomach, muscle, hypothalamus, pituitary gland, cerebrum, cerebellum, and hippocampus samples from six 150-day-old boars as well as ovary, uterus corners, cervix, and oviduct samples from three 150-day-old sows, were rapidly dissected after sacrifice and frozen in liquid nitrogen for tissue specific detection. Each right testis from 2- $(n=5), 30-(n=4)$, 60- $(n=3), 90-(n=3)$, and 150- $(n=6)$ day-old boars were obtained and frozen in liquid nitrogen for detection of developmental gene expression. Left testes were weighed and the left cauda epididymis was used to count sperm number [34]. 


\subsection{Total RNA Isolation and cDNA Synthesis}

Total RNA was extracted from frozen tissues using Trizol reagent (Invitrogen, Carlsbad, CA, USA) according to the manufacturer's instructions. RNA concentrations were quantified spectrophotometrically at $260 \mathrm{~nm}$. RNA ( $1 \mu \mathrm{g})$ was used to synthesize cDNA using the AM-MLV Reverse Transcriptase kit (Invitrogen) in a reaction volume of $50 \mu \mathrm{L}$. First strand cDNA $(1 \mu \mathrm{L})$ was used for PCR reactions.

\subsection{Cloning of Pig Stra8 Gene}

The Human stra8 CDS was used as a bait to obtain highly similar pig ESTs from dbESTs (National Center for Biotechnology Information, NCBI, Bethesda, MD, USA) using BLASTn. Primers were designed using primer 3.0 online [35] and used to confirm the sequence assembled by these dbESTs. The primers used were 5'-ATGGCAACCTCTGGAGAAGG-3' (forward) and 5'-CAGATCTTCGTCGTCA AATG-3' (reverse). PCR amplification in Meishan boar testis was performed using rTaq polymerase (Takara, Dalian, China) in a $25 \mu \mathrm{L}$ reaction mixture consisting of an initial 5 min denaturation step at $95{ }^{\circ} \mathrm{C}, 35$ cycles of $95{ }^{\circ} \mathrm{C}$ for $45 \mathrm{~s}, 56^{\circ} \mathrm{C}$ for $45 \mathrm{~s}, 72{ }^{\circ} \mathrm{C}$ for $1 \mathrm{~min}$, and a final extension for $10 \mathrm{~min}$ at $72{ }^{\circ} \mathrm{C}$. The amplified DNA fragments were subsequently cloned into pGEM-T Easy (Promega, Madison, WI, USA) and evaluated by Shanghai GeneCore BioTechnologies Co., Ltd. (Shanghai, China).

\subsection{5'-RACE (Rapid Amplification of cDNA Ends) and 3'-RACE}

Primers for 5'-RACE and 3'-RACE were designed based on the sequences obtained above. 5'-RACE was performed according to a previously described method [36,37]. Specific cDNAs were reverse transcribed in boar testes using the gene specific primer P51 (5'-CCTGGGGTTTCTGGAGTACA-3'). The first PCR cycle used special primer P52 (5'-TCTTGGCCTCCTCTAAGCTG-3') and the adaptor primers $\mathrm{Q}_{\mathrm{O}}$ and $\mathrm{Q}_{\mathrm{T}}$. Diluted PCR products were used in the second cycle with special primer P53 (5'-CTCAAGCACCTTCAGCTGTG-3') and adaptor primer $\mathrm{Q}_{\mathrm{I}}$ to amplify the 5'-end fragment. PCR programs for RACE reactions were similar to those described above.

3'-RACE was performed as described [36,38]. Testes cDNA was reverse transcribed using adaptor primer $\mathrm{Q}_{\text {T. }}$ The first cycle PCR used special primer P31 (5'-GTGCATGGAGACATTTGACG-3') and adaptor primer Qo. Diluted PCR products were used in the second cycle with special primer P32 (5'-GGCAGTCTCCAGGTTTGAAT-3') and adaptor primer $\mathrm{Q}_{\mathrm{I}}$ to amplify the 3'-end fragment. The second PCR products from 5'-RACE and 3'-RACE were cloned and sequenced. The full-length Stra 8 gene was assembled using these fragments and Megalign of DNASTAR (DNASTAR, Inc., Madison, WI, USA) and submitted to NCBI.

\subsection{Sequence Analyses}

The protein secondary structure using Predictprotein [39]. Coiled-coiled structures were predicted using COILS [40]. Conserved protein domains were identified using the SMART databases [41]. Amino acid similarities were performed using the Multiple Sequence Alignment Program Clustal W of the EMBL-EBI database [42] according to the default alignment parameters. Phylogenetic analyses of deduced amino acid alignments were performed by DNAMAN (LynnonBiosoft, Vaudreuil, QC, Canada) using the neighbor-joining method. 


\subsection{Semi-Quantitative RT-PCR}

Stra8 gene expression was investigated in different tissues from Meishan boars and sows using semi-quantitative RT-PCR. The forward primer 5'-ACCTCACAGCCTCAAAGTGG-3' and reverse primer 5'-CCTGGGGTTTCTGGAGTACA-3' were designed to detect tissue expression characteristics based on the sequences obtained above. RNA isolation, reverse transcription, and PCR programs were performed as described above. The $\beta$-actin gene (forward primer 5'-GCTGTATTCCCCTCCATCGT-3' and reverse primer 5'-ACGGTTGGCCTTAGGGTTCA-3') was used as a positive control. The number of PCR cycles (ranging from 25 to 35 cycles) was optimized for each gene. All experiments were repeated three times. PCR products were separated on ethidium bromide-stained $1.5 \%$ agarose gels.

\subsection{Quantitative Real-Time RT-PCR Assays}

Meishan boar testes tissue (2-, 30-, 60-, 90-, and 150-day-old) was used to evaluate the developmental expression of Stra8. Real-time PCR was performed using the 7500 System (ABI, Carlsbad, CA, USA) in a total volume of $20 \mu \mathrm{L}$ containing SYBR mix (10 $\mu \mathrm{L}$; Takara), primers (4 ng), and cDNA sample (50 ng) according to the manufacturer's instructions. Pig $\beta$-actin was used as an internal reference to normalize relative gene expression.

Stra 8 gene expression was measured using the $2^{-\Delta \Delta C t}$ method. According to the method, $\beta$-actin $C t$ values were used as the internal reference and Stra8 $C$ t values at 150 days were used as control. $\Delta \Delta C \mathrm{t}=\left(C \mathrm{t}_{\text {target genes }}-C \mathrm{t}_{\beta \text {-Actin }}\right)$ at $2,30,60$, and 90 days $-\left(C \mathrm{t}_{\text {target genes }}-C \mathrm{t}_{\beta \text {-Actin }}\right)$ at 150 days. All PCR products were run on ethidium bromide-stained agarose gels and confirmed using melting curve analyses to assess product quality.

\subsection{Construction of Expression Vectors}

Pig Stra8 cDNA was PCR-amplified from an adult boar testicular cDNA library using the method described above and EX-Taq polymerase (Takara). The PCR primers used were 5'-CCAAGCTT ATGGCAACCTCTGGAGAAGG-3' (forward) and 5'-CGCGGATCCCAGATCTTCGTCGTCAAA TG-3' (reverse) (Hind III and BamHI restriction sites underlined), which were constructed based on the sequence obtained above. PCR amplification consisted of an initial 5-min denaturation step at $96{ }^{\circ} \mathrm{C}$, followed by 35 denaturation cycles at $96{ }^{\circ} \mathrm{C}$ for $30 \mathrm{~s}$, annealing at $65^{\circ} \mathrm{C}$ for $30 \mathrm{~s}$ and extension at $72{ }^{\circ} \mathrm{C}$ for $1 \mathrm{~min}$, and a final 10-min extension. The resulting PCR products and EGFP-N1 vector (Clontech, Mountain View, CA, USA) were double digested with Hind III and BamHI restriction enzymes and ligated at $16^{\circ} \mathrm{C}$ for $16 \mathrm{~h}$ using $\mathrm{T} 4$ ligase (Takara).

Expression vectors were then transformed into E. coli DH5 . Clones were selected and identified using PCR and double enzyme digestion. Positive clones were confirmed by sequencing performed by Shanghai GeneCore BioTechnologies Co., Ltd., and were denoted EGFP-C1-pStra8. 


\subsection{Cell Culture and Subcellular Localization}

Pig SSCs were cultured in our lab from neonatal pig testis. The SSCs were isolated using the differential surface-attachment method $[43,44]$. The obtained cells were incubated for $4 \mathrm{~h}$ at $37{ }^{\circ} \mathrm{C}$ and $5 \% \mathrm{CO}_{2}$. The culture solution was then pipetted gently and placed into another culture flask. After $3 \mathrm{~h}$, the culture solution was pipetted again and the cells obtained in the culture media were purified as putative SSCs. Third generation SSCs and NIH/3T3 cells were transiently transfected to with Stra8 to evaluate its subcellular location. Cells were cultured in Dulbecco's Modified Eagle's Medium (DMEM), $10 \%$ fetal bovine serum, $100 \mathrm{U} / \mathrm{mL}$ penicillin, and $100 \mathrm{~g} / \mathrm{mL}$ streptomycin. All cells were grown at $37{ }^{\circ} \mathrm{C}$, and $5 \% \mathrm{CO}_{2}$. Lipofectamine ${ }^{\mathrm{TM}} 2000$ reagent (Invitrogen) was used for transfection according to the manufacturer's instructions. After overnight incubation at $37{ }^{\circ} \mathrm{C}$ in $5 \% \mathrm{CO}_{2}$, cells were imaged at room temperature using an inverted fluorescence microscope (Olympus, Shinjuku, Japan).

\subsection{Statistical Analyses}

All data are given as the mean \pm standard error. Statistical analyses were performed using least significant difference (LSD) tests with SPSS version 13.0 (IBM Corporation, Armonk, NY, USA). A $p$ value less than 0.05 was considered statistically significant.

\section{Conclusions}

In conclusion, this is the first report regarding pig Stra8 and its spatio-temporal expression pattern. Stra8 is thought to be meiotic gatekeeper gene, and its expression increases with age and bodyweight. Further studies are required to explain the function of Stra 8 as a potential transcription factor in meiosis initiation and to determine whether there are differences in phenotypes between various breeds of pig.

\section{Acknowledgments}

This study was funded by science fund in Yangzhou University (grant No. 2012CXJ075), the national science foundation of China (grant No. 31272406 and 31301959), a project funded by the priority academic program development of Jiangsu higher education institutions and research fund for the doctoral program of Yangzhou University.

\section{Author Contributions}

Xiaoyan Wang has done most of the experiment including cloning, expression analysis, transfection of the gene and writing the paper. Tingfeng Chen isolated and cultured pig SSCs. Chengyi Song did bioinformatics analysis, Bo Gao constructed the vector and Yani Zhang revised the paper.

\section{Conflicts of Interest}

The authors declare no conflict of interest. 


\section{References}

1. Borum, K. Oogenesis in the mouse: A study of the meiotic prophase. Exp. Cell. Res. 1961, 24, 495-507.

2. Hilscher, B.; Hilscher, W.; Bülthoff-Ohnolz, B.; Krämer, U.; Birke, A.; Pelzer, H.; Gauss, G. Kinetics of gametogenesis. Cell. Tissue Res. 1974, 154, 443-470.

3. McLaren, A. Meiosis and differentiation of mouse germ cells. Symp. Soc. Exp. Biol. 1984, 38, 7-23.

4. Speed, R.M. Meiosis in the fetal mouse ovary. Chromosoma 1982, 85, 427-437.

5. Koubova, J.; Menke, D.B.; Zhou, Q.; Capel, B.; Griswold, M.D.; Page, D.C. Retinoic acid regulates sex-specific timing of meiotic initiation in mice. Proc. Natl. Acad. Sci. USA 2006, 103, 2474-2479.

6. Bowles, J.; Knight, D.; Smith, C.; Wilhelm, D.; Richman, J.; Mamiya, S.; Yashiro, K.; Chawengsaksophak, K.; Wilson, M.J.; Rossant, J.; et al. Retinoid signaling determines germ cell fate in mice. Science 2006, 312, 596-600.

7. Li, H.; Palczewski, K.; Baehr, W.; Clagett-Dame, M. Vitamin A deficiency results in meiotic failure and accumulation of undifferentiated spermatogonia in prepubertal mouse testis. Biol. Reprod. 2011, 84, 336-341.

8. Clagett-Dame, M.; Knutson, D. Vitamin A in reproduction and development. Nutrients 2011, 3, $385-428$.

9. Raverdeau, M.; Gely-Pernot, A.; Féret, B.; Dennefeld, C.; Benoit, G.; Davidson, I.; Chambon, P.; Mark, M.; Ghyselinck, N.B. Retinoic acid induces Sertoli cell paracrine signals for spermatogonia differentiation but cell autonomously drives spermatocyte meiosis. Proc. Natl. Acad. Sci. USA 2012, 109, 16582-16587.

10. Oulad-Abdelghani, M.; Bouillet, P.; Décimo, D.; Gansmuller, A.; Heyberger, S.; Dollé, P.; Bronner, S.; Lutz, Y.; Chambon, P. Characterization of a premeiotic germ cell-specific cytoplasmic protein encoded by Stra8, a novel retinoic acid-responsive gene. J. Cell. Biol. 1996, 135, 469-477.

11. Bouillet, P.; Oulad-Abdelghani, M.; Vicaire, S.; Garnier, J.M.; Schuhbaur, B.; Dollé, P.; Chambon, P. Efficient cloning of cDNAs of retinoic acid-responsive genes in P19 embryonal carcinoma cells and characterization of a novel mouse gene, Stra1 (mouse LERK-2/Eplg2). Dev. Biol. 1995, 170, 420-433.

12. Menke, D.B.; Koubova, J.; Page, D.C. Sexual differentiation of germ cells in XX mouse gonads occurs in an anterior-to-posterior wave. Dev. Biol. 2003, 262, 303-312.

13. Zhou, Q.; Li, Y.; Nie, R.; Friel, P.; Mitchell, D.; Evanoff, R.M.; Pouchnik, D.; Banasik, B.; McCarrey, J.R.; Small, C.; et al. Expression of stimulated by retinoic acid gene 8 (Stra8) and maturation of murine gonocytes and spermatogonia induced by retinoic acid in vitro. Biol. Reprod. 2008, 78, 537-545.

14. Silva, C.; Wood, J.R.; Salvador, L.; Zhang, Z.; Kostetskii, I.; Williams, C.J.; Strauss, J.F., 3rd. Expression profile of male germ cell-associated genes in mouse embryonic stem cell cultures treated with all-trans retinoic acid and testosterone. Mol. Reprod. Dev. 2009, 76, 11-21.

15. Ohta, K.; Lin, Y.; Hogg, N.; Yamamoto, M.; Yamazaki, Y. Direct effects of retinoic acid on entry of fetal male germ cells into meiosis in mice. Biol. Reprod. 2010, 83, 1056-1063.

16. Childs, A.J.; Cowan, G.; Kinnell, H.L.; Anderson, R.A.; Saunders, P.T. Retinoic Acid signalling and the control of meiotic entry in the human fetal gonad. PLoS One 2011, 6, e20249. 
17. Ge, C.T.; Zhou, W.X.; Wang, W.; Li, C.Y.; Gao, Y.L.; Qian, G.Y. Retinoic acid directly regulates the initiation and completion of meiosis in chicken primordial germ cells. Sci. Sin. Vitae 2011, 41, 1167-1176.

18. Baltus, A.E.; Menke, D.B.; Hu, Y.C.; Goodheart, M.L.; Carpenter, A.E.; de Rooij, D.G.; Page, D.C. In germ cells of mouse embryonic ovaries, the decision to enter meiosis precedes premeiotic DNA replication. Nat. Genet. 2006, 38, 1430-1434.

19. Anderson, E.L.; Baltus, A.E.; Roepers-Gajadien, H.L.; Hassold, T.J.; de Rooij, D.G.; van Pelt, A.M.; Page, D.C. Stra8 and its inducer, retinoic acid, regulate meiotic initiation in both spermatogenesis and oogenesis in mice. Proc. Natl. Acad. Sci. USA 2008, 105, 14976-14980.

20. Feng, C.W.; Bowles, J.; Koopman, P. Control of mammalian germ cell entry into meiosis. Mol. Cell Endocrinol. 2014, 382, 488-497.

21. Snyder, E.M.; Small, C.; Griswold, M.D. Retinoic acid availability drives the asynchronous initiation of spermatogonial differentiation in the mouse. Biol. Reprod. 2010, 83, 783-790.

22. Lu, C.; Xu, M.; Wang, Y.; Qin, Y.; Du, G.; Wu, W.; Han, X.; Ji, C.; Yang, Y.; Gu, A.; et al. Genetic variants in meiotic program initiation pathway genes are associated with spermatogenic impairment in a Han Chinese population. PLoS One 2013, 8, e53443.

23. Bonache, S.; Algaba, F.; Franco, E.; Bassas, L.; Larriba, S. Altered gene expression signature of early stages of the germ line supports the pre-meiotic origin of human spermatogenic failure. Andrology 2014, 2, 596-606.

24. Cheng, P.L. A highly prolific pig breed of China- the Taihu breed. Parts I and II. Pig News Inf. 1983, 4, 407-425.

25. Lunstra, D.D.; Ford, J.J.; Klindt, J.; Wise, T.H. Physiology of the Meishan boar. J. Reprod. Fertil. Suppl. 1997, 52, 181-193.

26. Miyamoto, T.; Sengoku, K.; Takuma, N.; Hasuike, S.; Hayashi, H.; Yamauchi, T.; Yamashita, T.; Ishikawa, M. Isolation and expression analysis of the testis-specific gene, Stra8, stimulated by retinoic acid gene 8. J. Assist. Reprod. Genet. 2002, 19, 531-535.

27. Liu, J.; Zheng, Q.; Deng, Y.; Cheng, C.S.; Kallenbach, N.R.; Lu, M. A seven-helix coiled coil. Proc. Natl. Acad. Sci. USA 2006, 103, 15457-15462.

28. Murre, C.; Bain, G.; Dijk, M.A.V.; Engel, I.; Furnari, B.A., Massari, M.E.; Matthews, J.R.; Quong, M.W.; Rivera, R.R.; Stuiver, M.H. Structure and function of helix-loop-helix proteins. Biochim. Biophys. Acta 1994, 1218, 129-135.

29. Zhou, Q.; Nie, R.; Li, Y.; Friel, P.; Mitchel, 1.D.; Hess, R.A.; Small, C.; Griswold, M.D. Expression of stimulated by retinoic acid gene 8 (Stra8) in spermatogenic cells induced by retinoic acid: An in vivo study in vitamin A-sufficient postnatal murine testes. Biol. Reprod. 2008, 79, 35-42.

30. Xiongpin, J.; Jiatong, D. Research on maturity of testis and puberty of Erhualian boar (in Chinese). J. Sichuan Agric. Univ. 1998, 2, 234-236.

31. Biqin, F.; Jiafeng, H.; Duoxian, H.; Deshun, P.; Junliang, T.; Baoshen, Z. Research on reproductive characters of Erhualian Pig-Boar sex behavior and development of reproductive function. Anim. Husb. Vet. Med. 1980, 2, 4-8.

32. Stouffs, K.; Vandermaelen, D.; Tournaye, H.; Liebaers, I.; van Steirteghem, A.; Lissens, W. Genetics and male infertility. Verh. K. Acad. Geneeskd. Belg. 2009, 71, 115-139. 
33. Choi, Y.J.; Yoon, J.W.; Pyo, C.W.; Kim, J.A.; Bae, S.H.; Park, S.S. A possible role of STRA8 as a transcriptional factor. Genes Genomics 2010, 32, 521-526.

34. Engel, K.B. The Regulation and Toxicology of Spermatogenesis. Ph.D. Thesis, Boston University, Boston, MA, USA, 2008.

35. Untergrasser, A.; Cutcutache, I.; Koressaar, T.; Ye, J.; Faircloth, B.C.; Remm, M.; Rozen, S.G. Primer3-New capabilities and interfaces. Nucleic Acids Res. 2012, 40, doi:10.1093/nar/gks596.

36. Song, C.Y. Molecular Cloning of Several Pig Sperm Functional Genes and Characterization of Their mRNA Expression Profiles in the Genital Tracts and Ejaculated Sperm. Ph.D. Thesis, Yangzhou University, Yangzhou, China, 2010.

37. Scotto-Lavino, E.; Du, G.; Frohman, M.A. 5' end cDNA amplification using classic RACE. Nat. Protoc. 2006, 1, 2555-2562.

38. Scotto-Lavino, E.; Du, G.; Frohman, M.A. 3' end cDNA amplification using classic RACE. Nat. Protoc. 2006, 6, 2742-2745.

39. Yachdav, G.; Kloppmann, E.; Kajan, L.; Hecht, M.; Goldberg, T.; Hamp, T.; Hönigschmid, P.; Schafferhans, A.; Roos, M.; Bernhofer, M.; et al. PredictProtein-an open resource for online prediction of protein structural and functional features. Nucleic Acids Res. 2014, doi:10.1093/nar/gku366.

40. Lupas, A.; van Dyke, M.; Stock, J. Predicting coiled coils from protein sequences, Science 1991, $252,1162-1164$.

41. Letunic, I.; Doerks, T.; Bork, P. SMART 7: Recent updates to the protein domain annotation resource. Nucleic Acids Res. 2012, 40, 302-305.

42. Larkin, M.A.; Blackshields, G.; Brown, N.P.; Chenna, R.; McGettigan, P.A.; McWilliam, H.; Valentin, F.; Wallace, I.M.; Wilm, A.; Lopez, R.; et al. Clustal W and Clustal X version 2.0. Bioinformatics 2007, 23, 2947-2948.

43. Kuijk, E.W.; Colenbrander, B.; Roelen, B.A. The effects of growth factors on in vitro-cultured porcine testicular cells. Reproduction 2009, 138, 721-731.

44. Jia, Y.H. The Study of Isolation and Culture of Spermatcgonial Stem Cells of WZSP. Master's Thesis, Liaoning Normal University, Dalian, China, 2009.

(C) 2014 by the authors; licensee MDPI, Basel, Switzerland. This article is an open access article distributed under the terms and conditions of the Creative Commons Attribution license (http://creativecommons.org/licenses/by/3.0/). 